\title{
Is Nasobiliary Tube Really Safe? A Case Report
}

\section{Girolamo Geraci Enrico Maria Arnone Chiara Lo Nigro \\ Vita Maria Mirasolo Carmelo Sciumè Giuseppe Modica}

Division of Endoscopic Surgery, Section of General and Thoracic Surgery, University Hospital of Palermo, Palermo, Italy

\section{Key Words}

Nasobiliary tube $\cdot$ Complication $\cdot$ Esophagus

\begin{abstract}
A case of esophageal ulcer caused by nasobiliary tube is described. This tool is not routinely considered to be a cause of major complications in the literature and to our knowledge, this is the first report of this kind of complication in nasobiliary tube placement. A 72-year-old patient presented with Charcot's triad and was demonstrated to have cholangitis with multiple biliary stones in the common bile duct. Biliary drainage was achieved through endoscopic retrograde cholangiography, endoscopic sphincterotomy, biliary tree drainage and nasobiliary tube with double pigtail. The patient presented odynophagia, dysphagia and retrosternal pain $12 \mathrm{~h}$ after the procedure and upper endoscopy revealed a long esophageal ulcer, which was treated conservatively. This report provides corroboration of evidence that nasobiliary tube placement has potential complications related to pressure sores. In our opinion this is a possibility to consider in informed consent forms.
\end{abstract}

\section{Introduction}

In the setting of acute cholangitis caused by common bile duct stones, some endoscopists insert either an endoscopic nasobiliary tube or a biliary stent for decompression of infected bile. Although the nasobiliary tube can readily be placed safely in most cases, it may have shortcomings. A patient with a nasobiliary tube will experience discomfort in the nostril and face and will need a bile-collecting bag. There have been, however, few studies concerning the possible complications of the placement of a nasobiliary tube after clearance of the common bile duct. The aim of our paper is to report the first case in our experience of esophageal ulcer described in nasobiliary tube placement. 


\section{Case Report}

A 52-year-old lady, normally fit and well, presented with a 7-day history of jaundice and abdominal pain. She was nauseated and had dark urine and white stools. On clinical presentation, she was icteric and her temperature was $38.2^{\circ} \mathrm{C}$; she was hemodynamically stable. Systemic examination did not reveal any other abnormalities, specifically there were no stigmata of chronic liver disease. No organs or lymph nodes were palpable and the abdomen was soft and tender. Biochemical analyses demonstrated leukocytosis and neutrophilia: hemoglobin $(\mathrm{Hb}) 11.9 \mathrm{~g} / \mathrm{dl}$, white blood cell count $13.9 \times 10^{9} / \mathrm{l}$, neutrophils $11.4 \times 10^{9} / 1$. An acute phase response was evident with C-reactive protein $131 \mathrm{mg} / \mathrm{l}$ (normal 0.5-10 mg/l). A mixed cholestatic and hepatic picture of hepatic enzymes with alkaline phosphatase $195 \mathrm{U} / \mathrm{l}$ (normal 35-104 U/l), alanine aminotransferase $240 \mathrm{U} / \mathrm{l}$ (normal <31 U/l) and gamma-glutamyltransferase $181 \mathrm{U} / 1$ (normal 5-36 U/l) was demonstrated; total bilirubin was $8.25 \mathrm{mg} / \mathrm{dl}$ (normal $<1 \mathrm{mg} / \mathrm{dl}$ ). Hepatic synthetic function was preserved with albumin $30 \mathrm{~g} / \mathrm{l}$ and prothrombin time $13.8 \mathrm{~s}$. A clinical diagnosis of cholangitis was made on the basis of Charcot's triad (abdominal pain, fever and jaundice), and empirical antibiotic therapy (intravenous levofloxacin $100 \mathrm{ml}$ twice daily) was started.

Ultrasonography of the biliary tree demonstrated dilatation of the common bile duct to $1.5 \mathrm{~cm}$ with visualization of at least five stones (mean diameter $20 \mathrm{~mm}$ ) and biliary sludge in the lumen of the duct; intrahepatic duct dilatation was also noted. Endoscopic retrograde cholangiopancreatography was performed within $24 \mathrm{~h}$ of hospitalization with a side-viewing duodenoscope (TJF-145; Olympus Corporation, Hamburg, Germany) with the patient under sedation with fentanyl and midazolam; duodenal relaxation was obtained with scopolamine butylbromide and continuous cardiopulmonary monitoring was used. Cholangiography demonstrated multiple choledocholithiasis and endoscopic sphincterotomy was performed with a triple lumen sphincterotome (working length $1,950 \mathrm{~mm}$, channel size $2.8 \mathrm{~mm}$; Olympus, Hamburg, Germany); the extent of endoscopic sphincterotomy was determined by the size of the largest stone $(20 \mathrm{~mm})$. Five stones were removed with a basket without necessity of mechanical lithotripsy. The common bile duct was considered cleared when both the operating endoscopist and the radiologist agreed that no stone was seen on balloon occlusion cholangiography.

Anyway, it was decided to insert a nasobiliary tube (7 Fr tube with 9 side holes, length 2,550 mm, channel size $2.8 \mathrm{~mm}$, double pigtail $\alpha$ type) and the proximal end of it was lodged at the proximal common bile duct. The patient experienced odynophagia, dysphagia and retrosternal pain $12 \mathrm{~h}$ after the procedure (no evidence of hematemesis or vomiting). Biochemical analyses demonstrated no leukocytosis and reduction of cholestasis indexes but also anemia ( $\mathrm{Hb} 9.8 \mathrm{~g} / \mathrm{dl})$ with hemodynamic stability.

Under the suspicion of bleeding from papillotomy, after nasobiliary tube removal, esophagogastroduodenoscopy was performed, but the only endoscopic evidence was a long and isolated linear ulceration of the distal and middle esophagus, fibrin-covered and with hyperemic nonelevated margins (fig. 1). The patient received total parenteral nutrition and proton pump inhibitors $40 \mathrm{mg} / \mathrm{day}$ intravenously for 7 days. Biopsy specimens obtained from the margins of the ulcer revealed chronic phlogosis. Endoscopic and ultrasonographic surveillance were negative for unrecognized or residual stones and for esophageal lesions. Two-year follow-up was uneventful.

\section{Discussion}

Esophageal ulcers are a rare cause of upper gastrointestinal bleeding: in a surveillance of 7,564 esophagogastroduodenoscopies done by one surgeon at an urban hospital from 1991 to 2001, the etiology of esophageal ulcers included gastrointestinal reflux disease (GERD) in $65.9 \%$, drug-induced in $22.7 \%$, candidal in $3.4 \%$, caustic injury in $2.3 \%$ and herpes simplex virus, human immunodeficiency virus, marginal ulcer, foreign body, and unknown etiology each in $1.1 \%$. The mean size of GERD- and drug-induced esophageal ulcers was 2.78 and $2.92 \mathrm{~cm}$, respectively; $80.3 \%$ of GERD-induced and $13.8 \%$ of drug-induced esophageal ulcers were located in the lower thoracic esophagus. Morbidity 
$(44,5.8 \%)$ included hemorrhage (34\%), esophageal stricture (12.5\%) and esophageal perforation (3.4\%) [1].

At present there are no reports in the literature of esophageal ulcers related to nasobiliary tube. Endoscopic nasobiliary tube placement was described 30 years ago by Soehendra [2], but the placement technique has not changed: after positioning the nasobiliary tube within the biliary tree, the duodenoscope is withdrawn, leaving the tube exiting the mouth; a transfer tube (nasogastric tube) is passed transnasally; and finally, the endoscopist (or designee) passes his or her fingers into the patient's mouth to retrieve the transfer tube from the oropharynx to allow the nasobiliary tube to be transferred from mouth to nose [3].

The recognition of the limitations of sphincterotomy quickly led to the routine use of nasobiliary drainage to treat or prevent acute cholangitis by decompressing the proximal biliary tree. Although the use of nasobiliary and nasopancreatic drainage tubes actually preceded the advent of sphincterotomy, it greatly facilitated the technical aspects of the procedure, so that it had become an established therapeutic biliary procedure by the early 1980s [4].

The principal indications of nasobiliary tube are the management of cystic duct stump leak, endoscopic treatment of cholangitis and monitoring of incomplete common bile duct endoscopic clearance. The ability to monitor daily nasobiliary tube output and to perform repeat cholangiographies without subjecting the patients to multiple endoscopies permitted to manage cystic duct stump leak complicating cholecystectomy and precise determination of cystic duct stump leak closure with timely discharge, with the possibility of precise determination of cystic duct leak closure, final device removal without follow-up endoscopy, and ongoing decompression of the biliary tree after removal of the nasobiliary tube [5]. Moreover, approximately $15-30 \%$ of patients with acute cholangitis fail to respond to antibiotic therapy and require urgent biliary drainage to reverse the usual fatal septicemia of acute suppurative cholangitis. Most antibiotics, except for chinolonics, penetrate only poorly into the obstructed biliary system, but their excretion increases dramatically after the relief of the biliary obstruction, and the resulting chronic inflammation may lead to biliary strictures and promote formation of brown pigment stones, which are frequently infected by bacterial pathogens. The bacteria trapped within the brown pigment stones are isolated from bile and thus further hinder the antimicrobial treatment $[4,6]$.

Biliary drainage reduces mortality and speeds recovery from cholangitis and is therefore a vital part of management: Leung et al. [7] treated 105 of 350 patients with acute cholangitis who did not respond to antibiotics using various endoscopic methods. Endoscopic drainage was technically successful in $97 \%$ of patients and consisted of sphincterotomy and nasobiliary drainage tube placement in 64\%, nasobiliary drainage only in $23 \%$, and stone extraction with or without sphincterotomy in $13 \%$. Defervescence was observed within 3 days in $90 \%$ of patients, with a similar proportion of patients having biochemical improvement. The overall 30 -day mortality was $5 \%$ and limited to patients who initially presented with shock.

Pressure sores in the nose, inflammation in the posterior pharynx, granulations and injuries to the vocal folds are described to be related to use of the nasobiliary tube for a long time [8], but to our knowledge no esophageal ulcerations related to nasobiliary tube are described in the international literature. The endoscopic diagnosis of esophageal 
ulcers is rare (1.2\%) and is more frequent in complicated GERD (2.5\%) [1]. Patients with uncomplicated esophageal ulcers are normally treated with $\mathrm{H}_{2}$ blockers, proton pump inhibitors, or antifungal medication in the case of candidal esophageal ulcers. The mean length of stay for patients with uncomplicated esophageal ulcers is 6 days. Endoscopically confirmed resolution of esophageal ulcers has a mean resolution time of 49.8 days (range 4-150 days) [1].

\section{Conclusion}

This report confirms that nasobiliary tube placement, able to reduce mortality from cholangitis, is a harbinger of nonserious complications, not serious but important to know for the young and the experienced endoscopic surgeon to prevent the complication with the help of more expert colleagues. In our opinion, this rare complication should be added to informed consent forms.
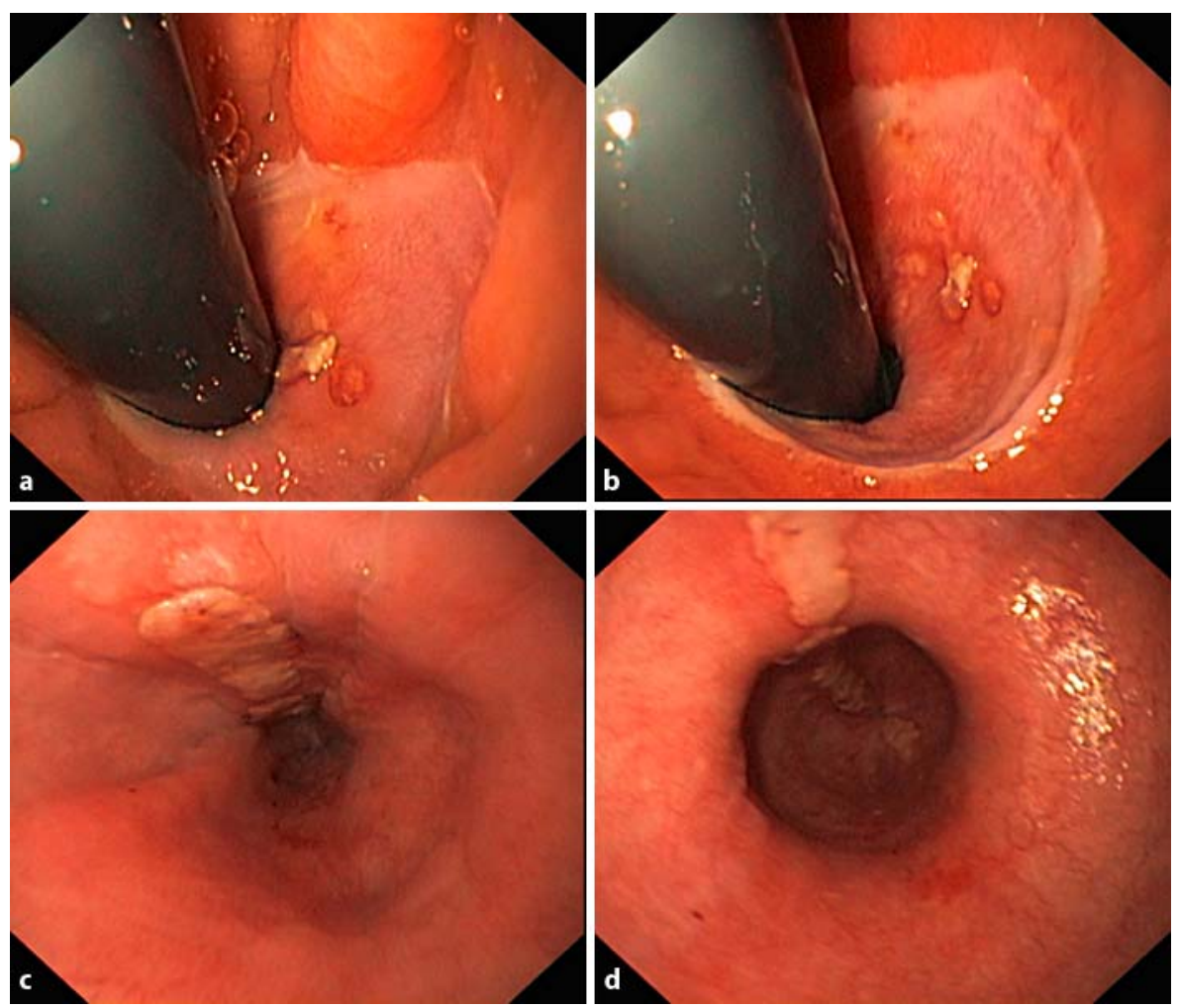

Fig. 1. Endoscopic aspect of esophageal ulcer. a, b Distal part of the esophagus visualized in retroversion: ulcer in the distal esophagus, fibrin-covered with hyperemic nonelevated margins and signs of decibitus. c, d Long and isolated linear ulceration of the distal and middle esophagus, fibrin-covered and with hyperemic nonelevated margins in correspondence to the previous site of the nasobiliary tube. 


\section{References}

$\checkmark 1$ Higuchi D, Sugawa C, Shah S, Tokioka S, Lucas CE: Etiology, treatment, and outcome of esophageal ulcers: a 10-year experience in an urban emergency hospital. J Gastrointest Surg 2003;7:836-842.

2 Soehendra N, Seifert H, Thonke F, Seitz U, Wang YG: Endoscopic techniques in therapy of choledocholithiasis. Chirurg 1994;65:413-417.

3 Baron TH: Transnasal endoscopy to facilitate nasobiliary tube placement: a simple and safe technique to avoid injury to the endoscopist. Endoscopy 2010;42:E323.

4 Lee JG: Role of endoscopic therapy in cholangitis. Am J Gastroenterol 1998;93:2016-2018.

5 Pinkas H, Brady PG: Biliary leaks after laparoscopic cholecystectomy: time to stent or time to drain. Hepatobiliary Pancreat Dis Int 2008;7:628-632.

6 Nagino M, Takada T, Kawarada Y, Nimura Y, Yamashita Y, Tsuyuguchi T, Wada K, Mayumi T, Yoshida M, Miura F, Strasberg SM, Pitt HA, Belghiti J, Fan ST, Liau KH, Belli G, Chen XP, Lai EC, Philippi BP, Singh H, Supe A: Methods and timing of biliary drainage for acute cholangitis: Tokyo Guidelines. J Hepatobiliary Pancreat Surg 2007;14:68-77.

7 Leung JWC, Chung SCS, Sung JJ, Banez VP, Li AK: Urgent endoscopic drainage for acute suppurative cholangitis. Lancet 1989;1:1307-1309.

$>8$ Baeten C, Hoefnagels J: Feeding via nasogastric tube or percutaneous endoscopic gastrostomy. Scand J Gastroenterol 1992;194:95-98. 